\title{
BMJ Open The realities of partnership in person- centred care: a qualitative interview study with patients and professionals
}

\author{
Axel Wolf, ${ }^{1,2}$ Lucy Moore, ${ }^{3}$ Doris Lydahl, ${ }^{4}$ Öncel Naldemirci, ${ }^{4}$ Mark Elam, ${ }^{4}$ \\ Nicky Britten ${ }^{3}$
}

To cite: Wolf $A$, Moore $L$, Lydahl D, et al. The realities of partnership in personcentred care: a qualitative interview study with patients and professionals. BMJ Open 2017;7:e016491. doi:10.1136/ bmjopen-2017-016491

- Prepublication history for this paper is available online. To view these files please visit the journal online (http://dx.doi org/10.1136/bmjopen-2017016491).

AW and LM contributed equally and are co-first authors.

Received 17 February 2017 Accepted 4 May 2017

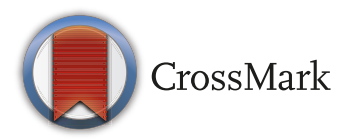

${ }^{1}$ Institute of Health Care Sciences, Sahlgrenska Academy, University of Gothenburg, Gothenburg, Sweden

${ }^{2}$ Gothenburg Centre for Person Centred Care (GPCC), University of Gothenburg, Gothenburg, Sweden

${ }^{3}$ Institute of Health Research, University of Exeter Medical School, Exeter, UK

${ }^{4}$ Department of Sociology and Work Sciences, University of Gothenburg, Gothenburg, Sweden

Correspondence to Dr Axel Wolf; axel.wolf@gu.se

\section{ABSTRACT}

Objective Although conceptual definitions of personcentred care (PCC) vary, most models value the involvement of patients through patient-professional partnerships. While this may increase patients' sense of responsibility and control, research is needed to further understand how this partnership is created and perceived. This study aims to explore the realities of partnership as perceived by patients and health professionals in everyday PCC practice.

Design Qualitative study employing a thematic analysis of semistructured interviews with professionals and patients.

Setting Four internal medicine wards and two primary care centres in western Sweden.

Participants 16 health professionals based at hospital wards or primary care centres delivering person-centred care, and 20 patients admitted to one of the hospital wards.

Results Our findings identified both informal and formal aspects of partnership. Informal aspects, emerging during the interaction between healthcare professionals and patients, without any prior guidelines or regulations, incorporated proximity and receptiveness of professionals and building a close connection and confidence. This epitomised a caring, respectful relationship congruent across accounts. Formal aspects, including structured ways of sustaining partnership were experienced differently. Professionals described collaborating with patients to encourage participation, capture personal goals, plan and document care. However, although patients felt listened to and informed, they were content to ask questions and felt less involved in care planning, documentation or exploring lifeworld goals. They commonly perceived participation as informed discussion and agreement, deferring to professional knowledge and expertise in the presence of an empathetic and trusting relationship.

Conclusions In our study, patients appear to value a process of human connectedness above and beyond formalised aspects of documenting agreed goals and care planning. PCC increases patients' confidence in professionals who are competent and able to make them feel safe and secure. Informal elements of partnership provide the conditions for communication and cooperation on which formal relations of partnership can be constructed.

\section{Strengths and limitations of this study}

This study reports the experiences of both patients and professionals in hospital settings that have implemented an evidence-based model of personcentred care

- The study population consisted of professionals with a broad range of clinical experience and patients with diverse medical signs and symptoms.

- Our sample was not designed to be statistically representative.

\section{INTRODUCTION}

Increasingly, clinicians are encouraged to engage, inform and involve patients $^{12}$ and support health policies that promote patient-led care through 'activated' patients trained in self-management skills. ${ }^{3}$ Health professionals and policy makers aspire towards person-centred care (PCC),${ }^{5-7}$ and recent models of PCC prioritise a whole systems approach that places patients at the centre. ${ }^{8-10}$ It is clear that with professional support, patients can become active partners in their care $\mathrm{e}^{11-15}$ and can benefit from opportunities to take part. ${ }^{16-18}$ However, despite the development of PCC and the push towards patient professional partnerships, ${ }^{8}$ there is much talk and little action. ${ }^{719-21}$ Substantial organisational and cultural barriers exist ${ }^{20} 22-24$ and in order to overcome these barriers, both patients and professionals need to feel engaged, respected and treated as equals. ${ }^{211} 121425-27$ To date, there are numerous care concepts such as patient-centred care, individualised care and narrative medicine that touch on patient involvement and partnership, all including some sort of reciprocity and shared knowledge, $^{28} 29$ self-management ${ }^{30} 31$ and participation in decision making. ${ }^{32}$ Different PCC frameworks lift patient involvement towards an enhanced therapeutic relationship that requires sharing power and 
responsibility. ${ }^{6}$ Yet, as patients are increasingly offered more choice and involvement, researchers also describe circumstances where patients choose to decline participation, defer decisions or feel unable to participate. ${ }^{33}{ }^{34}$ It seems that the notion of the patient as an active partner in care requires empirical understanding and clarity.

Cribb and Entwistle draw attention to the importance of an emotionally supportive patient-professional partnership to aid 'meaningful participation' and shared decision making. ${ }^{14}$ Relationships that are open ended and conversational are prioritised as well as professional virtues and patient capabilities. This approach takes into account the relational aspects of partnership, which pay attention to the mindfulness of professionals and the unique aspects of patients' lives. ${ }^{53} 36$ However, although power sharing implies an egalitarian and meaningful patient-professional relationship, ${ }^{29}$ the literature describes a hierarchy of relationships depicting the different levels of engagement, responsibility and shared goals. ${ }^{31}{ }^{37}$ This moves from the lowest level, that is involvement towards participation, and the highest level, that is, partnership. ${ }^{37}$ Thórarinsdóttir and Kristjánsson elaborate on informal and formal relationships; the former describing the fundamental importance of human connectedness and the latter involving shared agreements on decisions and documentation. ${ }^{31}$

In this paper, we use a Swedish initiative for implementing an evidence-based PCC model as a case study. The University of Gothenburg Centre for PCC (GPCC) has introduced a new evidence-based model, ${ }^{38-41}$ supported by a programme of training and research, which has changed clinical practice. ${ }^{42}$ This model consists of three 'routines' of PCC, namely narrative, partnership and documentation. ${ }^{39} 4243$ Partnership in the GPCC framework is the main routine that drives the PCC process. The person's narrative paves the way for collaboration, and documentation safeguards this collaboration. The aim of this study is to explore the realities of partnership as perceived by patients and health professionals in everyday PCC practice.

\section{Methods}

Sample and design

This study adopted an interpretive approach employing qualitative semistructured interviews. We used a purposive sampling strategy to capture several professional categories and a convenience sampling approach for patients (table 1). Four internal medicine wards at a large teaching hospital in west Sweden were chosen; these varied in size (18-36 hospital beds), specialisation and patient group (patients with chronic and/or acute illness and from self-managing to bed confined). Each ward took part in a 10-week PCC change management/training programme, incorporating both lectures and workshops regarding the ethics of PCC, research findings from PCC studies as well as training in using different tools such as care plans and interview techniques. The ward manager chose members of staff (registered nurse (RN), assistant nurse (AN) and
Table 1 Description of practitioners and patient demography

\begin{tabular}{lc}
\hline & Health professionals (n=17) \\
\hline Women (n) & 14 \\
Profession & 5 \\
\hline Registered nurse & 4 \\
\hline Assistant nurse & 4 \\
\hline Manager & 4 \\
\hline Physician & $29-60$ min \\
\hline Interview range & \\
\hline Place for interview & 13 \\
\hline Hospital & 2 \\
\hline Primary care centre & 2 \\
\hline University & Patient (n=20) \\
\hline & 11 \\
\hline Women (n) & 69, 35-88years \\
\hline Age median (range) & $19-83$ min \\
\hline Interview range & 13 \\
\hline Place for interview & 2 \\
\hline Home & 1 \\
\hline Hospital & 4 \\
\hline University & \\
\hline Telephone & \\
\hline
\end{tabular}

physicians) as designated change agents in the training programme and to implement PCC to their colleagues on each ward.

Each ward manager was contacted with information about the study and gave their consent. They were then asked to recruit a nurse, an assistant nurse and a physician, with experience of working with PCC and from the training programme, from their ward.

Patients were eligible for enrolment into the study if they were cognisant, able to communicate in Swedish and admitted to a internal medicine ward where PCC was being implemented at the hospital.

This ward had implemented PCC systematically using a 10-week extensive training course facilitated by GPCC following the PCC routines. ${ }^{38}$

A nurse coordinator working on the ward provided eligible patients with the study information. Twenty-one patients volunteered to participate and gave their informed consent to be contacted by the study team after discharge and to be interviewed about the care they had received. One patient was excluded when transferred from another ward to the ward, which hampered recall.

\section{Data collection}

The interview guide for practitioners included questions about how PCC related to the everyday work of healthcare practitioners and its implementation. The interview guide for patients was intended to elicit patients' experiences 
Table 2 Interview guide practitioners and patients

\section{Interview guide: health professionals}

- To start with, could you tell me a bit about this ward/clinic/ centre?

Prompts: Size? Practical work? Team?

- How did you start working with PCC?

Prompts: First contact with PCC? When did you first hear about it? Where did the idea come from? Did you have a special training?

- How did you implement PCC in the ward/clinic/centre? What did the implementation look like?

- Could you tell me about a regular day at work with PCC?

- Tell me about your practice and experiences with PCC on this ward/clinic/centre?

- How would you describe PCC to someone who is coming to work with you on your ward/centre?

Prompts: How would you describe or define PCC?

How did patients react to PCC?

Would you tell me about any changes to your practice since you started working with PCC?

Prompts: Were there any changes in your ways of working?

Relations with patients? Routines? Division of labour? Any changes-adaptions?

- What kind of documentation do you use when you work with PCC? Do you use any tools, diaries, notebooks, written material as part of PCC during your day? Can you describe this for me? How do you use this documentation for PCC in your work?

What kinds of conditions do you think are required for PCC?

What kinds of things do you think helped PCC and what kinds of things made PCC difficult in your experience?

Is there anything else you would like to add?

\section{Interview guide: patients}

- Could you tell me about your experience of the care you received? How would you describe the care and treatment?

Prompts: Can you give examples of the kind of care you received? What did the routines look like?

- How have you experienced the relationship between you and the staff? How did you experience the communication between you and the staff?

Prompts: In which ways, did you receive information? Did you discuss your care and treatment with the staff? Did the staff listen to your concerns and questions?

- What has been important to you in the care that you received?

Prompts: How did you participate in decisions, have you been seen and listened to, information and communication about your care and treatment? Do you think that your resources/knowledge have been utilised?

Do you think that the care you received was different from the care you have experience in the past and (if applicable) the care that you received later?

Prompts: In what way did they differ? What changes have you noticed?

- Are you familiar with the term person-centred care?

Prompts: If so, how would you describe PCC?

D During the care process, which part(s) of the care and treatment received do you perceive were person centred?

Which parts of PCC meant the most to your experience of involvement/partnership?

Prompts: Could you give some examples? Procedures? Documentation? How staff looked after you? Something else?

Do you think that health professionals have been interested in you as a person?

- Did you use an electronic health diary via the app or the web?

Prompts: How important was it for you? If not, did you use any other form of documentation tools or aids that had meaning for you?

Is there anything else you would like to add?

PCC, person-centred care.

of care on the ward and their understanding of PCC (table 2).

DL conducted 12 interviews with professionals, AW conducted 2, and a trained research assistant conducted 3 interviews with practitioners and all interviews with patients.

All interviews were audio-recorded, transcribed verbatim, anonymised and translated from Swedish into English. They were then read and checked by the team to ensure accuracy and fluency. Translation was literal, yet for specific idioms in Swedish which are not easy to translate, native English speakers in the research team suggested alternatives that would do better justice to the content, and bilingual team members checked their accuracy. Any potential misinterpretations were clarified and agreed. All interviewees were given a numbered pseudonym to maintain confidentiality $(\mathrm{P}$ for patient, $\mathrm{N}$ for nurses, $\mathrm{M}$ for manager and $\mathrm{MD}$ for physician). All participants were told that they were free to withdraw their consent at any time during the study. Patients were interviewed after their hospital stay, in a place of their choosing to ensure that they felt comfortable talking about the care episode. A research assistant $(\mathrm{MH})$ without a clinical background or connection to the hospital performed all patient interviews. However, she is trained sociology and had previous experience of conducting patient interviews. She received guidance from the team concerning the interview guide, qualitative interview techniques and the use of probing questions throughout the present study. Probing 
questions were used to follow-up a topic of discussion, to obtain a better illustration of the discussed topics and facilitate the dialogue in a way that the interviewees felt comfortable responding to questions. If interviewees did not want to talk more about a particular issue, the interviewer skipped the related probing questions and asked the following question in the guide.

The regional ethics committee in Gothenburg approved the study, and all participants, prior to their interview, gave informed consent. If the patients wanted to talk to a healthcare professional about general or specific topics that came up during the interviews, they were able to talk to a nurse about their concern or thoughts.

\section{ANALYSIS}

Interviews were thematically analysed, adopting some basic features of grounded theory. The interviews were analysed initially employing line-by-line coding and an inductive, intuitive reading of the transcripts. Transcripts were independently coded by LM, ÖN and DL, summarised and then discussed by online and face-to-face meetings. A combination of computer software (NVivo V.9) and hand-written methods were used and mind mapping to assist with the development of themes. ${ }^{44} \mathrm{We}$ then followed a deductive process to explore how the characteristics and components of partnership were experienced by professionals and patients. Early analysis identified categories associated with providing comfort, creating confidence and finding common ground through everyday informal interactions. In contrast, other categories revealed formalised care provided by professionals such as exchanging information, planning, evaluating and documenting care. However, when these were compared with patient transcripts, patients described a simplified and practical process such as receiving some form of paperwork and knowing what was done. As analysis progressed, we categorised these findings under two main themes: informal and formal aspects of partnership. These findings were discussed with the whole team in order to address differences and reach a consensus.

\section{RESULTS}

Two main themes were found: first, informal aspects of partnership comprising two subthemes, proximity and receptiveness, and building a personal connection/confidence. Informal aspects of partnership were interpreted as those emerging during the interaction between healthcare professionals and patients. The second main theme was formal aspects of partnership having two subthemes, aspects of goal setting and care planning, and documentation. Formal partnership is about the structured ways of sustaining the relationship between the health professionals and the patients via deciding goals, care planning and documentation. The results are presented below to allow comparison between the two groups.
Informal aspects of partnership

Proximity and receptiveness

Professionals described engaging patients in conversation with the intention of respecting and listening to the patient, understanding the patient's situation, making a good start and building a close connection. Assistant nurses followed this process each morning and described feeling 'closer' to the patient, seeing and hearing aspects of the patient from a social, psychological and physical perspective and becoming their 'eyes and ears'. Professionals described using communication techniques such as posing open, straightforward questions, talking without distractions and not judging. A number of professionals felt this process aided partnership in subsequent meetings.

I think that I and the nurse get a great response from the patients, straight away, that they feel very comfortable in this. They know who to turn to. That they feel like they've been given a lot of time, even if it's not that long time, but the content of the consultation gives them that feeling. (MD1)

Many patients described positive feelings towards the receptiveness of staff and the atmosphere of the ward. Accounts of unhurried and immediate support with care provided in a caring and close manner were common.

Not everyone sits down at your bedside, just a few of them do. Mostly they pull out chair or something to sit on. They are not on their way to another patient when they do that. It's more of a good opening; that we are sitting here now, talking, until we are finished doing that. (P1)

Available and reliable professionals increased patients' comfort, with professionals described as thoughtful, open and warm, leading to patients feeling a sense of humanity, security, familiarity and trust.

They say 'Hi Paula!' and then they present themselves with their name and then the title comes. Already there they create an opportunity for dialogue. It's not 'I'm nurse, good day.' So at that point it feels like an openness and they simply and easily describe how my life will be in this room. (P2)

\section{Building a close connection and confidence}

Professionals described listening in a more engaged way to patients' wishes and needs. They emphasised the importance of knowing how patients felt, what they thought, aspects of their personality and personal knowledge, described by one professional as 'life-luggage'. Patients were prompted to discuss personal interests and common topics. For most professionals finding common ground built trust, security and a collaborative relationship on a person-to-person level.

You may talk about books or music, or common interests so that you're not only... You establish a 
relationship beyond the nurse-patient, and it becomes more like person to person. (N1)

In keeping with professionals' aspirations, many patients felt listened to and acknowledged. Several felt known personally, for who they were and their individual needs.

They could ask ordinary questions about the everyday life. We could talk about summer houses, and pets, and kind of on that level. And that's... I think that's very important. I think so at least... one is feeling more as if you aren't just a patient among others. (P3)

Some patients reported that they noticed changes in professionals' receptiveness.

I was thinking that I should ask him to sit down, but you know how it is, no. But I can think that it's a different situation. He stands there taller than me who's sitting on the bedside. I don't like that....But what I regret is that I wasn't able to look at my x-rays on CT-abdomen. I had asked for that previously, but I didn't receive an answer to that. Well, I might have said that I wanted to see my x-rays. It can be interesting to look with a physician, because I know nothing about... I can't do it myself. So I asked for that the last day, but she said that she was much stressed, the assistant physician, and she had had very much to do. I would have wanted that. I'm sure I will get them to my home. I have requested everything and my medical records, but I can't examine things like those. It wasn't anything, but it would have been interesting to look at it. Sit with a doctor and review it. (P4)

However, other patients paid less attention to this change in professionals' receptiveness since they considered their hospitalisation as brief and requiring straightforward treatment.

\section{FORMAL PARTNERSHIP}

\section{Goal setting and care planning}

Professionals reported working in partnership with patients in formal ways by giving and exchanging information, updating, summarising and care planning. For example, patients are encouraged to discuss aspects of their symptoms, treatment, diagnosis and discharge plans. A number of professionals described making a 'team decision', alternatively known as a health plan, in collaboration with patients. This acknowledged a person's capabilities and personal goals that were agreed, documented and given to the patient. This is in line with the PCC routine of safeguarding the partnership through agreed goals.

The patient when at the hospital together with the nurse and the doctor decided what are the main issues: is it losing weight, is it anxiety, is it stop smoking or getting better medication or is it more training, physical activities, is it fear of training? And so on. So when they left the hospital they had this sheet where they had described their problem and it was just, it was their problem it was not a standard formula - the formula was standard but the questions and the wishes from the patient was personal (MD2)

Informal aspects of partnership led to an environment where it became possible for patients to ask questions and learn about their condition and treatment. Professionals believed patients had the inclination to begin caring for themselves, follow suggestions and instructions. Formal aspects such as discussing goals facilitated self-care such as getting dressed, mobilising on the ward, preparing for discharge and following advice postdischarge.

Several professionals described the need to encourage, 'push' or' pass' on competence to the patient, by letting the patient ask questions and take part in the care planning, hence enabling the patient to become well informed, knowledgeable and take responsibility.

There is a more practical understanding that the patient also carries a responsibility, and also is responsible for the process. I tend to think that my ward is at this stage of the process - to get the patient to understand the significance of his or her participation to activity, to rehabilitation. (M1)

Professionals noticed a change, where patients who were well informed, knew they had an impact, influence and could handle themselves. They seemed satisfied and more willing to help themselves and 'buy the whole concept'.

We look at what the patient usually does in their everyday life outside the hospital, and what the patient does right now, and what we can do to improve and to support that the patient becomes their ordinary self again. And that you really try to understand how they can use their own resources and train themselves. (N2)

However, from the patient's perspective, some remembered taking part in developing a health plan, but few mentioned goals, and when discussed, these were invariably described in medicalised terms or framed around home circumstances for discharge. Personal information was elicited and described but not necessarily orientated towards 'lifeworld' goals.

I don't actually know if the goal has been mentioned, but that might be the goal with the illness I have, that the goal is to be free from relapses. Because everything would then be as good as they can be. One wouldn't suffer from the disease then. As long as one takes medicine that doesn't give side-effects and isn't suffering from relapses, then everything will be okay. And I know that has been mentioned, that it might be the goal after all. But that, as I said, that has to do with the disease. (P5)

Patients felt they contributed when they discussed choices with professionals, helped themselves, used their initiative 
and became knowledgeable. There were opportunities to question, decline treatment and contribute to discharge planning. For some, participation involved discussing test results, investigations and medication management that helped them 'feel' (our emphasis) they were committed to taking part in their care, for example, by discussing an ultrasound test, a transfusion or a colonoscopy procedure. They received explanations and felt they knew what to do, how to deal with medication and treatments.

I know much more about my illness now and why it has become the way it has, I think I understand that better now. And that I can see in hindsight that I haven't been feeling well for a very long time, which has been connected to this. So now I have got a much clearer picture of my condition. (P6)

Others felt they participated by listening to professionals, agreeing and accepting professionals' decision making. They felt confident, comfortable and treated as equals, described by one patient as 'horizontal communication'. A few patients described themselves as 'experienced', 'verbal' even when very ill and able to 'demand and ask questions'. Yet for patients in this study, participating was described in terms of informed discussion, acceptance and agreement, participating up to a point or as far as they felt able. Several felt comfortable 'submitting' and 'not being in the driving seat'.

Many times one might feel like one is participating... one sometimes may be silent, but still feel a fellowship. Do you understand what I mean? And that's probably what I felt with the ward. That I didn't need to ask or I didn't need to ask them, the nurses I mean, since I knew in some way that the community still was there. (P7)

When I say no to something, theylisten to me. Whatever it might be; the discharge or anything. Or some kind of examination... I said no to an examination, and I said that: 'You did that examination just six months ago, and it's very painful. Is it really necessary to do it again?' 'No, then we won't do it.' (P1)

Since you are part of the treatments, and you know how they are doing the plan for the treatment and are explaining in a good way. So even when you return home, you know approximately about... Well, now I know how I will deal with the medications and the treatment and everything, in a completely different way. (P7)

\section{Documentation}

Professionals described writing care plans with patients, eliciting biomedical information and discussing social and discharge planning. Decisions and plans were agreed and documented.

You should make a plan together with the patient and that you discuss with the patient and so on, but the difference of having it in this way is that you have more of a structure of it. You create a framework for what it means to work like this, so that what you're doing becomes more concrete. (MD3)

In some way the patient gets what we've done on paper, and we get a proof of that we understand it in the right way, so that the patient can say 'Yes, this is how it was' or 'I don't agree with this.' The important thing is that you agree, so that you are on the same page so to speak. (N1)

In this respect professionals described 'a new practice' where patients were encouraged to actively participate, become more involved and take part in decisions about their care.

Documentation acted as a reminder for patients to discuss care on 'a new level'. (N3)

You must create a care plan with the patient within 48 hours and then you should write why they have sought care and what we have planned for them and this should be addressed at the round with the patient, and it is written down and then it's a little investigation to see what the patients can do themselves. (N4)

Professionals encouraged patients to use their own resources and expertise. For example, patients were encouraged to prepare for conversations with the team and write down thoughts or questions.

Patients felt informed about their condition, discharge and future care needs, felt they were listened to and some felt they were participating in their care plan.

I think, that it felt like it was a team. Decisions where I participated in, and the care plan and such things. How much you actually were that, I don't know, but at least you had a picture of it, so. But I can't decide how I'm going to be treated or taken care of, but at least you can be a part of it and have opinions, you were able to do that. (P8)

Although patients remembered receiving written information and some described opportunities to write down thoughts, questions and contribute to their care, they did not remember the written information in any detail. Nevertheless, patients saw this documentation in 'simple' terms whereby they felt taken care of and in receipt of sufficient information.

\section{Discussion}

In our study, interviewees' accounts reflect levels of mutuality, self-expression and respect that lay the groundwork for PCC and indicate a move from disease-focused models of care. ${ }^{19}$ In keeping with the literature, we suggest that informal elements of partnership provide the conditions for communication and mutual cooperation on which formal relations of partnership can be constructed. ${ }^{27} 3136$ Professional and patient perspectives highlight the importance of the informal elements of partnership for ultimately determining the level of shared 
decision making, which is possible to aspire to and practically achieve. ${ }^{14}$ Informal elements in our study depict emotionally supportive relationships that pave the way for patients to participate, once the scene is set and the circumstances feel right.

However, in our findings, patients were content to be able to ask questions and receive information. They perceived participation as informed discussion and agreement, deferring to professional knowledge and expertise and not necessarily describing opportunities for empowerment and activation. Perceived competence of professionals seemed enough for patients and while patients prioritised the informal processes where 'good care' may have been interpreted as PCC, professionals prioritised outcomes that were formal and documented.

Patients described participating in plans for discharge but did not describe notions of enablement or control. As with other studies, patients were satisfied with a personal approach and a positive partnership with professionals who communicated empathetically and effectively ${ }^{45}$ with professionals acting as educators, building mutual and collaborative partnerships. ${ }^{46}$ Measurements of optimum patient-professional relationships and person centredness need to consider patients' emotional and personal responses that highlight the process rather than the outcome of interactions with health professionals. ${ }^{514} 2735$ Aspects of informal and formal partnership appeared to act as antecedents of patient participation. Yet overall, most patients portrayed a taken-for-granted pragmatism, trusting professionals with expertise and competence to make overall decisions in a caring environment. For patients in this study, PCC was not explicitly understood or described as an opportunity to formalise a partnership with professionals in order to actively participate in their care. There were more informal aspects of partnership that took precedence in patients' minds, which is in line with the description of the fundamentals of human connectedness described by Thórarinsdóttir and Kristjánsson, pointing towards the ethical dimension of partnership and PCC. In addition, ${ }^{31}$ professionals may have considered PCC as a particular professional approach rather than a systematic endeavour to 'invite' patients to participate in the PCC routines and explicate the model.

Aspects of partnership, particularly informal aspects, led patients to leave some decisions to the professionals since they felt cared for and well informed. Patients were not forced to make a choice, but they were rather given guidance and information. In this respect, patients' interpretation of participation can be viewed, not as passive submission or deferment to professional expertise and knowledge, but a common understanding reached through a therapeutic relationship. Our interpretation of the present study points towards the importance of human connectedness and the feeling of being listened to and acknowledged as a person (informal aspect) for patients, while routines and formal aspects of care came more into the foreground for the practitioners. It seems as if in order to integrate the patient into clinical practice, there seems to be a balancing act that practitioners as well as patients need to reflect on: recognition of the patient as a person (informal aspects) needs to balance the specific practical routines (formal aspects). ${ }^{42}$ The risk could otherwise be that the patient as a person becomes a 'tickbox' in a routine, which in many aspects would entrench profession-centred care rather than person centredness.

This study has some limitations. Patients did not necessarily perceive their care in the context of a PCC model and our study depended on patients remembering events and perhaps perceiving the relevance of information and care strategies. Second, because the study took place in a particular institutional context (GPCC) in Sweden, the findings may not be transferable to other settings. Formal aspects of partnership, for example, documented care plans and decisions, could have provided patients with opportunities to revisit decisions in written form, and maintain a sense of confidence and trust during their admission that was taken for granted. Most interviewees were older perhaps predisposing them to comply with professional expertise or feel knowledgeable but not necessarily empowered. ${ }^{47}$ Ekdahl et at $t^{48}$ suggest that older peoples' preferences for information and decision making are not fully acknowledge and/or acted on by the healthcare professional. Patients aged 75 years and above may want more information relating to their care, without having to ask. Therefore, healthcare professionals need to be receptive and responsive to patients' preferences and tailor the information and decision-making process accordingly.

Another limitation in this study is that patients were first contacted by a nurse coordinator, and after agreeing to be part of the study, participants were contacted by the researchers after their discharge within the first 7 days to schedule an interview. Patients who agreed to participate in the interview study might have been more attentive to the particular aspects of PCC and eager to talk about their experience. This might have led to the tendency for positive accounts about the informal parts of partnership. However, it is equally important for the objective of the study to capture positive comments about partnership.

\section{Conclusion}

In our study, patients appear to value a process of human connectedness above and beyond formal aspects of taking part and feeling activated and capable. These findings may point to the need for professionals to acknowledge the importance of the human connectedness that is as crucial as formal aspects in order for PCC to be fully realised in practice.

Contributors AW and LM contributed equally and are co-first authors. All authors contributed to the study design, conception and development. DL and AW conducted the interviews together with a research assistant Marie Hammer. All authors were responsible for critical revision and finalising the manuscript.

Funding The study was funded by the Centre for Person-Centred Care (GPCC) and LETStudio at the University of Gothenburg, Sweden. GPCC is funded by the Swedish Government's grant for Strategic Research Areas, Care Sciences (Application to 
Swedish Research Council No. 2009-1088) and cofunded by the University of Gothenburg, Sweden. Nicky Britten was partially supported by the National Institute for Health Research (NIHR) Collaboration for Leadership in Applied Health Research and Care South West Peninsula.

Disclaimer The views expressed are those of the authors and not necessarily those of the NHS, the NIHR or the Department of Health. The authors are grateful to the interviewees for their willingness to participate in the study.

Competing interests NB is a member of the Scientific Advisory Board of GPCC. The author(s) declared no potential conflicts of interest with respect to the research, authorship, and/or publication of this article.

Patient consent We used a Swedish template for the patient consent form reviewed by the regional ethical review board.

Ethics approval Regional Ethical Board Gothenburg Sweden.

Provenance and peer review Not commissioned; externally peer reviewed.

Data sharing statement No additional data are available.

Open Access This is an Open Access article distributed in accordance with the Creative Commons Attribution Non Commercial (CC BY-NC 4.0) license, which permits others to distribute, remix, adapt, build upon this work non-commercially, and license their derivative works on different terms, provided the original work is properly cited and the use is non-commercial. See: http://creativecommons.org/ licenses/by-nc/4.0/

(C) Article author(s) (or their employer(s) unless otherwise stated in the text of the article) 2017. All rights reserved. No commercial use is permitted unless otherwise expressly granted.

\section{REFERENCES}

1. Elwyn G, Frosch D, Thomson R, et al. Shared decision making: a model for clinical practice. J Gen Intern Med 2012;27:1361-7.

2. Elwyn G, Lloyd A, May C, et al. Collaborative deliberation: a model for patient care. Patient Educ Couns 2014;97:158-64.

3. Department of Health. Long term conditions compendium of information. 2012.

4. Eaton S, Roberts S, Turner B. Delivering person centred care in long term conditions. BMJ 2015;350:h181.

5. Epstein RM, Street RL. The values and value of patient-centered care. Ann Fam Med 2011;9:100-3.

6. Harding E, Wait S, Scrutton J. The state of play in person-centred care: pragmatic review of how person-centred care is defined, applied and measured, featuring selected key contributors and case studies across the field. : The Health Foundation 2015:1-140.

7. Hawkes N. Seeing things from the patients' view: what will it take? BMJ 2015;350:g7757.

8. Health Foundation. Helping people help themselves. 2011.

9. Fund King's. People in control of their own health and care. 2014.

10. England NHS. Enhancing the quality of life for people living with long term conditions-the house of care,. 2014.

11. Coulter A. Patient engagement--what works? J Ambul Care Manage 2012;35:80-9.

12. Coulter A, Collins A. Making shared decision-making a reality; no decision about me, without me. London: The King's Fund 2011:1-40.

13. Coulter A, Safran D, Wasson JH. On the language and content of patient engagement. J Ambul Care Manage 2012;35:78-9.

14. Cribb A, Entwistle VA. Shared decision making: trade-offs between narrower and broader conceptions. Health Expect 2011;14:210-9.

15. Makoul G, Clayman ML. An integrative model of shared decision making in medical encounters. Patient Educ Couns 2006;60:301-12.

16. Amin F. Commentary: becoming a person centred practice. BMJ 2015;350:h269.

17. National Voices. Principles of care and support planning, 2013.

18. Coulter A, Entwistle VA, Eccles A, et al. Personalised care planning for adults with chronic or long-term health conditions. Cochrane Database Syst Rev 2015;3:CD010523.

19. Ekman I, Swedberg K, Taft C, et al. Person-centered care--ready for prime time. Eur J Cardiovasc Nurs 2011;10:248-51.

20. Frosch DL. The patient is the most important member of the team. BMJ 2015;350:g7767.

21. Frosch DL, May SG, Rendle KA, et al. Authoritarian physicians and patients' fear of being labeled 'difficult' among key obstacles to shared decision making. Health Aff 2012;31:1030-8.
22. Moore L, Britten N, Lydahl D, et al. Barriers and facilitators to the implementation of person-centred care in different healthcare contexts. Scand J Caring Sci 2016.

23. Naldemirci Ö, Lydahl D, Britten N, et al. Tenacious assumptions of person-centred care? exploring tensions and variations in practice. Health 2016.

24. Alharbi TS, Ekman I, Olsson LE, et al. Organizational culture and the implementation of person centered care: results from a change process in Swedish hospital care. Health Policy 2012;108:294-301.

25. Gravel K, Légaré F, Graham ID. Barriers and facilitators to implementing shared decision-making in clinical practice: a systematic review of health professionals' perceptions. Implement Sci 2006;1:16.

26. Entwistle VA. Considerations of 'fit' and patient involvement in decision making. Health Expect 2006;9:95-7.

27. Entwistle VA, Watt IS. Patient involvement in treatment decisionmaking: the case for a broader conceptual framework. Patient Educ Couns 2006;63:268-78.

28. Hudon C, Fortin M, Haggerty J, et al. Patient-centered care in chronic disease management: a thematic analysis of the literature in family medicine. Patient Educ Couns 2012;88:170-6.

29. Mead N, Bower P. Patient-centredness: a conceptual framework and review of the empirical literature. Soc Sci Med 2000;51:1087-110.

30. Sahlsten MJ, Larsson IE, Sjöström B, et al. An analysis of the concept of patient participation. Nurs Forum 2008;43:2-11.

31. Thórarinsdóttir K, Kristjánsson K. Patients' perspectives on personcentred participation in healthcare: a framework analysis. Nurs Ethics 2014;21:129-47.

32. Frank C, Asp M, Dahlberg K. Patient participation in emergency care - a phenomenographic analysis of caregivers' conceptions. J Clin Nurs 2009;18:2555-62.

33. Eldh AC, Ehnfors M, Ekman I. The phenomena of participation and non-participation in health care--experiences of patients attending a nurse-led clinic for chronic heart failure. Eur J Cardiovasc Nurs 2004;3:239-46.

34. Eldh AC, Ekman I, Ehnfors M. Conditions for patient participation and non-participation in health care. Nurs Ethics 2006;13:503-14

35. Epstein RM. Making communication research matter: what do patients notice, what do patients want, and what do patients need? Patient Educ Couns 2006;60:272-8.

36. Epstein RM, Franks P, Fiscella K, et al. Measuring patient-centered communication in patient-physician consultations: theoretical and practical issues. Soc Sci Med 2005;61:1516-28.

37. Cahill J. Patient participation: a concept analysis. J Adv Nurs 1996;24:561-71.

38. Ekman I, Wolf A, Olsson LE, et al. Effects of person-centred care in patients with chronic heart failure: the PCC-HF study. Eur Heart $J$ 2012;33:1112-9.

39. Fors A, Ekman I, Taft C, et al. Person-centred care after acute coronary syndrome, from hospital to primary care - A randomised controlled trial. Int J Cardiol 2015;187:693-9.

40. Feldthusen $\mathrm{C}$, Dean $\mathrm{E}$, Forsblad-d'Elia $\mathrm{H}$, et al. Effects of personcentered physical therapy on fatigue-related variables in persons with rheumatoid arthritis: a randomized controlled trial. Arch Phys Med Rehabil 2016;97:26-36.

41. Olsson LE, Hansson E, Ekman I. Evaluation of person-centred care after hip replacement-a controlled before and after study on the effects of fear of movement and self-efficacy compared to standard care. BMC Nurs 2016;15:53.

42. Britten N, Moore L, Lydahl D, et al. Elaboration of the Gothenburg model of person-centred care. Health Expect 2017;20.

43. Ekman I, Hedman H, Swedberg K, et al. Commentary: Swedish initiative on person centred care. BMJ 2015;350:h160.

44. Miles MB, Huberman AM, Saldana J. Qualitative data analysis: $A$ methods sourcebook. Third ed. London: Sage Publications, 2014.

45. Little P, Everitt $\mathrm{H}$, Williamson I, et al. Observational study of effect of patient centredness and positive approach on outcomes of general practice consultations. BMJ 2001;323:908-11.

46. Roter $\mathrm{D}$. The enduring and evolving nature of the patient-physician relationship. Patient Educ Couns 2000;39:5-15.

47. Joseph-Williams N, Elwyn G, Edwards A. Knowledge is not power for patients: a systematic review and thematic synthesis of patientreported barriers and facilitators to shared decision making. Patient Educ Couns 2014;94:291-309.

48. Ekdahl AW, Andersson L, Wiréhn AB, et al. Are elderly people with co-morbidities involved adequately in medical decision making when hospitalised? A cross-sectional survey. BMC Geriatr 2011;11:46. 